\title{
Separation of phenols and ketones from bio-oil produced from ethanolysis of
}

\section{wheat stalk}

\author{
Hua-Mei Yang a,b, Wei Zhao ${ }^{\text {a, }}{ }^{\text {, }}$, Koyo Norinaga ${ }^{\text {b }}$, Jun-Ji Fang ${ }^{\text {a }}$, Yu-Gao Wang ${ }^{\text {a }}$, Zhi-Min Zong ${ }^{\text {a }}$, \\ Xian-Yong Wei ${ }^{\text {a,* }}$
}

${ }^{a}$ Key Laboratory of Coal Processing and Efficient Utilization, Ministry of Education, China University of Mining and Technology, Xuzhou 221116, Jiangsu, China

${ }^{b}$ Institute for Materials Chemistry and Engineering, Kyushu University, Kasuga 816-8580, Fukuoka, Japan.

* To whom correspondence should be addressed. (W.Z.) Telephone: +86 (516) 83995916. E-mail: zhaow1965@163.com. (X.-Y.W.) Telephone: $\quad+86 \quad$ (516) 83884399. E-mail: wei_xianyong@163.com.

\section{ABSTRACT}

To realize a high-efficient utilization of bio-oil, extraction-column chromatography was employed to separate bio-oil produced by ethanolysis of wheat stalk. Extraction was employed to separate bio-oil roughly by acid, alkaline solutions as well as organic solvents, and column chromatography was used to enrich chemicals with petroleum ether, or mixture of acetone/carbon disulfide as elution solvent. Bio-oil and all sub-fractions were determined by gas chromatography-mass spectrometry. $\mathrm{C}_{8}-\mathrm{C}_{30}$ alkanes were enriched in petroleum elution sub-fractions, with a concentration of $97.6 \%$. Phenols were efficiently enriched in a high concentration $\sim 100 \%$ by elution of acetone/carbon disulfide. What's more, ketones were also separated efficiently from bio-oil in this study. (C) 2015. This manuscript version is made available under the Elsevier user license http://www.elsevier.com/open-access/userlicense/1.0/ 1 
Acetophenone was enriched with a concentration of $71.2 \%$ in a sub-fraction $\left(\mathrm{ES}_{\mathrm{b} 1}\right)$ eluted by mixture of acetone/carbon disulfide. 2-hydroxy-cyclopentenones was enriched in a sub-fraction $\left(\mathrm{ES}_{\mathrm{d} 4}\right)$ with a concentration of $52.6 \%$.

Keywords: bio-oil; extraction; column chromatography; phenols; acetophenone; cyclopentenones.

\section{Introduction}

Biomass has been walking into our life and industries as an interesting renewable resources used to provide second generation biofuels or chemicals [1,2]. Abundant amount and $\mathrm{CO}_{2}$ neutrality with low sulfur and nitrogen content make biomass a sustainable and eco-friendly energy source [3]. Bio-oil, a liquid product from thermal conversion of biomass, has been paid attention to provide fuels and chemicals [4-6]. The bio-oil is a complicated liquid mixture consisting of hundreds of compounds (especially oxy-compounds), and exhibits a high water content, high oxygen content, low heating value, and high acidity [4,7-9]. The poor fuel quality of bio-oil makes it unsuitable to be used directly as vehicle fuel, and the compounds complexity makes it difficult to upgrade the

fuel qualities of bio-oil [7]. Recently, increasing attention has been paid to the recovery of chemicals from bio-oil. Providing chemicals compared to fuels could make recovery of even small concentrations viable [5]. As we all know, most of the oxy-compounds such as phenols, ketones, and alcohols are value-added chemicals used in industry and life. Until now, most of oxygen-containing chemical stocks are mainly produced from fossil fuels via oxidation or hydration of olefins to introduce oxygen-containing functional groups. Fortunately, these functional groups have already existed in bio-oil. Hence, providing value-added chemicals from bio-oil is a potential 
approach to efficiently utilize biomass energy.

Distillation, extraction and column chromatography are three common methods for separation.

Distillation separates the bio-oil in different fractions by the boiling-point. Amen-Chen et al. [10] have summarized the literatures of the fractional distillation and flash distillation of bio-oil. The thermal and chemical instability of bio-oil leads to a low distillation yield and coke formation during distillation $[7,10]$. Recently, molecular distillation was introduced to separate bio-oil, which can increase the distillates yields and lower the formation of coke [11-13]. Bio-oil was mainly separated in light fraction (main compounds: acetic acid and 1-hydroxy-2-propanone), middle fraction (main compounds: phenols, aldehyde, and ketones), and heavy fraction (main compounds: levoglucosan) by molecular distillation $[11,14,15]$. Considering the mild condition, extraction and column chromatography has been employed to separate bio-oil. Table 1 summarizes the literatures which focused on the separation of bio-oil by extraction and column chromatography $[2,7,8,16-26]$. Extraction is always used as bench-scale separation technique of bio-oil and has been widely investigated to produce phenols and sugars (such as levoglucosan and glycolaldehyde) from bio-oil as Table 1 lists. Acid and alkaline solutions are always employed to separate phenols from bio-oil. Wang et al. [7] obtained a phenolic fraction with a high concentration of $94.35 \%$ through liquid-liquid extraction with acid and alkaline solutions and carbon dichloride. Zilnik et al. [20] tried to recover phenolic fractions from various bio-oil by two schemes and found that methyl isobutyl ketone combined with alkali solution is efficient for extraction of phenolic compounds. Recently, organic solvent liquid-liquid extraction without acid and alkaline solutions was 
investigated by Wei et al. [21] and a fraction with $85 \%$ of phenols was obtained. Different from extraction, column chromatography is efficient in chemical purification. As Table 1 shows, separation of bio-oil by single column chromatography always gives three fractions (aliphatic, aromatic and polar fractions) [23-26]. The aliphatic fraction is determined as mixture of alkane and alkene [25], while aromatic and polar sub-fractions are paid less attention. By multi-steps column chromatography, Das et al. [22] separated cardanol, cardol, di-n-octyl phthalate, bis (2-ethylhexyl) phthalate, and di-n-decyl phthalate from pyrolysis oil, and Zeng et al. [2] obtained five fractions, mainly containing phthalate esters. Considering the high consumption of solvents, column chromatography was suggested as a final purification step of chemicals from bio-oil [10].

The objective of this study is to isolate possible chemicals such as phenols and ketones from bio-oil at a laboratory scale. Extraction and column chromatography were combined to separate bio-oil, and provide possible chemicals. The bio-oil was produced by ethanolysis of wheat stalk. Liquid-liquid extraction was employed to separate bio-oil in different chemical classes. Column chromatography was used to enrich chemicals into sub-fractions with petroleum ether, or mixture of acetone/carbon disulfide as elution solvent. $\mathrm{C}_{8}-\mathrm{C}_{30}$ alkanes, phenols, acetophenone and cyclopentenones were enriched efficiently. Different from the separation of phenols from bio-oil, publications on separation of ketones from bio-oil are very limited. Acetophenone and cyclopentenones were also separated with high content from bio-oil in this study.

\section{Experimental}

\subsection{Wheat stalk and reagents}


The wheat stalk used in this study was collected from Xuzhou, Jiangsu Province, China. It was pulverized and passed through an 80-mesh sieve and dried in a vacuum oven at $105{ }^{\circ} \mathrm{C}$ for $3.5 \mathrm{~h}$. Proximate, ultimate, and chemical analyses of the sample was reported previously [27]. All the organic solvents, including benzene, petroleum ether (PE; bp. $30-60{ }^{\circ} \mathrm{C}$ ), acetone, carbon disulfide $\left(\mathrm{CS}_{2}\right)$, and diethyl ether (DEE), used in this study were analytical reagents and distilled prior to use. Adsorbent silica gel (SG, 100-200 mesh) was activated in a vacuum oven at $145^{\circ} \mathrm{C}$ for $6 \mathrm{~h}$.

\subsection{Production of bio-oil from wheat stalk}

The bio-oil used in this study was produced from wheat stalk depolymerization in supercritical ethanol. Detailed information about the production of bio-oil has been published elsewhere [27]. 10 $\mathrm{g}$ wheat stalk and $300 \mathrm{~mL}$ ethanol were placed into a $1 \mathrm{~L}$ magnetically stirred autoclave. After drawing air out from the autoclave, the autoclave was heated to $300{ }^{\circ} \mathrm{C}$ and kept at $300{ }^{\circ} \mathrm{C}$ for $0.5 \mathrm{~h}$, and then immediately cooled to room temperature in an ice-water bath. The reaction mixture was taken out from the autoclave as exhaustively as possible with added ethanol and filtrate through a polytetrafluoroethylene membrane filter with $0.8 \mu \mathrm{m}$ of pore size. The filter cake was repeatedly washed with ethanol and the solution was also filtrated through the filter. Bio-oil (named as SEB) was obtained by evaporating the filtrate with a rotary evaporator.

\subsection{Extraction of bio-oil}

As exhibited in Fig. 1, $4 \mathrm{~g}$ SEB was added into $50 \mathrm{~mL}$ benzene and stirred well under ultrasonication. Benzene insoluble phase (BIP) was removed by filtration, and was washed by 50 $\mathrm{mL}$ benzene, repeatedly three times. The benzene soluble phase was subsequently mixed with 200 
$\mathrm{mL}$ water, stirring constantly for $20 \mathrm{~min}$. After 60 minutes' standing, two layers were obtained: an upper aqueous phase $\left(\mathrm{WP}_{\mathrm{I}}\right)$ and a bottom benzene phase $\left(\mathrm{BSP}_{\mathrm{I}}\right)$. $\mathrm{WP}_{\mathrm{I}}$ was added to $200 \mathrm{~mL} \mathrm{DEE}$, stirring for $20 \mathrm{~min}$, and standing 60 minutes. DEE soluble phase and insoluble phase were separated and distillated to support DEE soluble phase I (DEEP $)$ and DEE insoluble phase I (DEEIP $)$. The

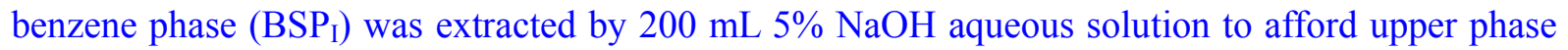
$\left(\mathrm{BSP}_{\mathrm{II}}\right)$, middle phase (precipitate), and lower phase $(\mathrm{NaOH}$ aqueous phase). The precipitate was washed by acetone to afford acetone-extractable portion (ASP), and the residue was named acetone-insoluble portion (AIP). The $\mathrm{NaOH}$ aqueous phase was neutralized with $5 \% \mathrm{HCl}$ aqueous solution to $\mathrm{pH}$ 6-7, and then extracted with $200 \mathrm{~mL}$ DEE. Two layers (DEE soluble phase and insoluble phase) were separated and distillated to support DEE soluble phase II (DEEP II) and DEE insoluble phase II (DEEIP $\left.{ }_{\mathrm{II}}\right)$.

\subsection{Column chromatography of extracted fractions}

Separation of column chromatography was carried out for the extracted fractions $\mathrm{BSP}_{\mathrm{II}}, \mathrm{DEEP}_{\mathrm{I}}$, and DEEP ${ }_{\text {II. }}$ (1) $0.2 \mathrm{~g} \mathrm{BSP}_{\mathrm{II}}$ was dissolved in $1 \mathrm{~mL}$ benzene, and then adsorbed by $0.5 \mathrm{~g} \mathrm{SG}$. After

dried at room temperature, the mixture was transferred into a $2 \mathrm{~cm}$ inner diameter, SG-packed column (Height of SG-packed column of $50 \mathrm{~cm}$ ). The $\mathrm{BSP}_{\mathrm{II}}$ was sequentially eluted with $7.5 \mathrm{~L}$ and 9.3 L PE to afford sub-fractions $\mathrm{ES}_{\mathrm{c} 1}$ and $\mathrm{ES}_{\mathrm{c} 2}$. (2) $0.2 \mathrm{~g} \mathrm{DEEP}_{\mathrm{I}}$ was dissolved in $1 \mathrm{~mL} \mathrm{CS}_{2}$, and then adsorbed by $0.5 \mathrm{mg} \mathrm{SG}$. After dried at room temperature, the mixture was transferred into a 1 cm inner diameter, SG-packed column (Height of SG-packed column of $27 \mathrm{~cm}$ ). Firstly, the DEEP was eluted with $300 \mathrm{~mL}$ isometric $\mathrm{CS}_{2}$ /acetone mixed solvent to collect the first color bar in the 
column (namely $\mathrm{ES}_{\mathrm{b} 1}$ ). The residue was eluted with $500 \mathrm{~mL}$ isometric $\mathrm{CS}_{2}$ /acetone mixed solvent to afford the second sub-fractions $\left(\mathrm{ES}_{\mathrm{b} 2}\right)$. (3) $0.2 \mathrm{~g} \mathrm{DEEP}_{\mathrm{II}}$ was dissolved in $1 \mathrm{~mL} \mathrm{CS}_{2}$, and then adsorbed by $0.5 \mathrm{mg} \mathrm{SG}$. After dried at room temperature, the mixture was transferred into a $1 \mathrm{~cm}$ inner diameter, SG-packed column (Height of SG-packed column of $27 \mathrm{~cm}$ ). Different from DEEP there was no color bar observed for DEEP $_{\text {II }}$ separation. The DEEP $\mathrm{II}$ was successively eluted with $200 \mathrm{~mL}, 300 \mathrm{~mL}, 300 \mathrm{~mL}$, and $500 \mathrm{~mL}$ isometric $\mathrm{CS}_{2} /$ acetone mixed solvent to afford four sub-fractions $\left(\mathrm{ES}_{\mathrm{d} 1}-\mathrm{ES}_{\mathrm{d} 4}\right)$.

\subsection{Analysis of SEB and sub-fractions}

SEB and all the sub-fractions were analyzed with gas chromatography-mass spectrometry (GC-MS, Hewlett-Packard 6890/5973) equipped with a capillary column coated with HP-5MS (cross-link 5\% PH ME siloxane, $60 \mathrm{~m}$ length, $0.25 \mathrm{~mm}$ inner diameter, $0.25 \mu \mathrm{m}$ film thickness) and a quadrupole analyzer in electron-impact mode at $70 \mathrm{eV}$. The column temperature was held at $50{ }^{\circ} \mathrm{C}$ for $2 \mathrm{~min}$, raised to $200{ }^{\circ} \mathrm{C}$ at a rate of $3{ }^{\circ} \mathrm{C} \min ^{-1}$ and then to $300{ }^{\circ} \mathrm{C}$ at a rate of $10{ }^{\circ} \mathrm{C} \mathrm{min}{ }^{-1}$ followed by holding the temperature for $8 \mathrm{~min}$. Mass spectra were scanned from 30 to 500 amu. In addition, ASP and AIP were also analyzed with a Nicolet Magna IR-560 Fourier transform infrared

(FTIR) spectrometer by collecting 50 scans at a resolution of $8 \mathrm{~cm}^{-1}$ in reflectance mode with measuring region of $4000-400 \mathrm{~cm}^{-1}$.

\section{Results and discussion}

\subsection{Chemical composition of SEB}

The SEB is a dark and sticky liquid. The total ion chromatogram (TIC) of SEB is shown in Fig. 
SI1 (Supporting Information), and all of the organic compounds of SEB detected by GC-MS are listed in Table SI1. Main compounds in SEB are listed in Table 2, including 2 hydrocarbons, 9 phenols, 3 ethers, 4 tetrahydrofurans, 6 esters, and 1 acid. In total, 121 compounds were detected in the SEB, and classified into nine chemical families: hydrocarbons, alcohols, phenols, ethers, esters, tetrahydrofurans, aldehydes, ketones, carboxylic acids, and others. Total area \% of each chemical families decrease in the order: esters $(33.4 \%)>$ phenols $(28.4 \%)>$ ketones $(10.6 \%)>$ tetrahydrofurans $(10.3 \%)>$ hydrocarbons $(6.9 \%)>$ ethers $(5.3 \%)>$ alcohols $(2.4 \%)>$ acids $(1.3 \%)>$ aldehydes $(0.8 \%)>$ others $(0.7 \%)$. In SEB, esters, phenols, ketones, and tetrahydrofurans are major components. Hereafter, the percentage value refers to area percent (area \%), if there is no special explain.

\subsection{Extraction of SEB}

The detailed extraction procedure has been illustrated in Fig.1. SEB was extracted into eight fractions, and the yield of each extracted fractions are given in Table 3. Totally, $92.8 \%$ were recovered after the extraction. All the fractions were analyzed by GC-MS. There are no peaks observed in the TICs of benzene insoluble phase (BIP), DEE insoluble phase I and II (DEEIP I $_{\text {and }}$ DEEIP $_{\mathrm{II}}$ ), acetone soluble phase (ASP), and acetone insoluble phase (AIP). This would be caused by the limitation of GC-MS for the detection of polar compounds or heavy molecular compounds.

The TICs of benzene soluble phase II $\left(\mathrm{BSP}_{\mathrm{II}}\right)$, DEE soluble phase I $\left(\mathrm{DEEP}_{\mathrm{I}}\right)$, and DEE soluble phase II $\left(\right.$ DEEP $\left._{\text {II }}\right)$ are given in Fig. SI-2, Fig. SI-3, and Fig. SI-4. The main compounds (area\% $\geq$ $1 \%$ ) in $\mathrm{BSP}_{\mathrm{II}}, \mathrm{DEEP}_{\mathrm{I}}$, and $\mathrm{DEEP}_{\mathrm{II}}$ are listed in Table 4, Table 5, and Table 6. 
Extraction can enrich phenols from SEB in DEEP ${ }_{\mathrm{I}}$ and DEEP $\mathrm{II}$, with an area $\%$ of $29.7 \%$ and $73.0 \%$, respectively. Phenols in $\mathrm{DEEP}_{\mathrm{I}}$ are mainly polyhydroxyl benzenes (PHBs), while dominant phenols in $\mathrm{DEEP}_{\mathrm{II}}$ are monohydroxybenzenes (MHBs) with alkyl and/or methoxyl substituents. Except phenols in $\mathrm{DEEP}_{\mathrm{I}}$, ketones are another main chemical family with an area $\%$ of $31.6 \%$. Ketones in $\mathrm{DEEP}_{\mathrm{I}}$ are mainly acetophenone and its derivatives, and hydroxycyclopentenone (HCP) and its derivatives $\left(8.5 \%\right.$ and $15.9 \%$, respectively). The composition of $\mathrm{BSP}_{\mathrm{II}}$ is more complex than that of $\mathrm{DEEP}_{\mathrm{I}}$ and $\mathrm{DEEP}_{\mathrm{II}}$. Ketones (mainly alkyl-cyclopentenones) and esters (mainly diesters) are two main families in $\mathrm{BSP}_{\mathrm{II}}$, with an area $\%$ of $31.7 \%$ and $31.0 \%$, respectively.

Ester is one of main chemical families in SEB. And our unpublished data shows that $\mathrm{C}_{8}-\mathrm{C}_{28}$ fatty acid esters can be separated from SEB by column chromatography. However, esters were not detected in eluted sub-fractions which will be discussed in next section. FTIR was employed to find the trace of esters. Fig. 2 shows the FTIR spectra of ASP and AIP. The peaks at 3425 and $910 \mathrm{~cm}^{-1}$, $1702 \mathrm{~cm}^{-1}, 1183 \mathrm{~cm}^{-1}$ were due to vibrations of $-\mathrm{OH}, \mathrm{C}=\mathrm{O}$, and $\mathrm{C}-\mathrm{O}$, respectively. Thus, the compounds in this fraction were mainly acids. Moreover, the peaks at 2974, 2933, 1464, and 1367 $\mathrm{cm}^{-1}$ were attributed to vibrations of $-\mathrm{CH}_{2}$ and $-\mathrm{CH}_{3}$. The peak at $721 \mathrm{~cm}^{-1}$ was due to the rocking vibration of $-\left(\mathrm{CH}_{2}\right)_{n}-(\mathrm{n}>4)$. It was inferred that the compounds in ASP were mainly fatty acid. The spectrum of AIP in Fig. 2 is simple, only four peaks at 2929, 2871, 1584, and $1403 \mathrm{~cm}^{-1}$, which are typical peaks for fatty acid salt. In this study, $\mathrm{NaOH}$ solution was employed to basify $\mathrm{BSP}_{\mathrm{I}}$. It can be inferred that the main compounds in AIP should be fatty acid sodium.

\subsection{Enrichment of chemicals from sub-fractions}


BSP $_{\mathrm{II}}, \mathrm{DEEP}_{\mathrm{I}}$, and DEEP $\mathrm{II}$ were further separated by SG-packed column with elution solvent PE for $\mathrm{BSP}_{\mathrm{II}}$ and isometric $\mathrm{CS}_{2}$ /acetone mixture for $\mathrm{DEEP}_{\mathrm{I}}$ and $\mathrm{DEEP}_{\mathrm{II}}$. The TICs of eluted sub-fractions are illustrated in Fig. 3 and Fig. 4, and compounds identified by GC-MS are summarized in Table 7, Table 8, and Table 9. $\mathrm{C}_{8}-\mathrm{C}_{30}$ alkanes, MHBs, benzenediols, acetophenone, and HCPs are enriched efficiently as discussed below.

\subsubsection{Enrichment of $C_{8}-C_{30}$ alkanes}

As Fig. 3 and Table 7 show, alkanes with $\mathrm{C}_{8}-\mathrm{C}_{30}$ (except $\mathrm{C}_{11}$ ) and $\mathrm{C}_{18}-\mathrm{C}_{30}$ are predominant in $\mathrm{ES}_{\mathrm{c} 1}$ and $\mathrm{ES}_{\mathrm{c} 2}$ with an area \% of $55.9 \%$ and $97.2 \%$, respectively. After stored in shade for 10 days, milk-white solids $\left(\mathrm{ES}_{\mathrm{c} 1-\mathrm{w}}\right.$ and $\left.\mathrm{ES}_{\mathrm{c} 2-\mathrm{w}}\right)$ were obtained from $\mathrm{ES}_{\mathrm{c} 1}$ and $\mathrm{ES}_{\mathrm{c} 2}$. Reprecipitated by $\mathrm{PE}$, the milk-white solids were analyzed with GC-MS as alkanes with $\mathrm{C}_{12}-\mathrm{C}_{30}$ in $\mathrm{ES}_{\mathrm{c1-w}}$ and $\mathrm{C}_{18}-\mathrm{C}_{30}$ in $\mathrm{ES}_{\mathrm{c} 2-\mathrm{w}}$.

\subsubsection{Enrichment of phenolic compounds}

As a necessary industry chemical, the main resource of phenols is coal tar. With the large depletion of coal, the production of phenols from bio-oil is being paid attention $[7,14,16,17]$. In SEB employed in this study, phenols are second dominant compounds. Producing phenols from SEB is very attractive. 35 phenols are collected with extraction-column chromatography, which are expected to be the promising resource to meet the demand of phenol market. As Fig. 4 and Fig. 5 show, phenols were efficiently enriched in $\mathrm{ES}_{\mathrm{d} 1}, \mathrm{ES}_{\mathrm{d} 2}$ and $\mathrm{ES}_{\mathrm{d} 3}$, with an area \% of $82.3 \%, 100 \%$ and 64\%, respectively. $\mathrm{ES}_{\mathrm{d} 1}$ is a mixture of MHBs (69.8\%) and PHBs (12.5\%) with hydroxyl-

acetophenone (15.8\%). $\mathrm{ES}_{\mathrm{d} 2}$ mainly consists of 4 guaiacols with an area $\%$ of $95.7 \%$, including 
guaiacol (18.6\%), 4-methylguaiacol (8.3\%), 4-ethylguaiacol (49.4\%), and 4-propylguaiacol (14.4\%).

The dominant compound in $\mathrm{ES}_{\mathrm{d} 3}$ is syringol (2,6-dimethoxylphenol) with an area \% of 57.2\%.

PHBs were mainly collected in $\mathrm{ES}_{\mathrm{b} 2}$ with an area \% of 55.6\%, mainly including catechol (16.3\%),

3-methylcatechol (11.4\%), 4-methylcatechol (10.7\%), and 4-ethylcatechol (16.4\%).

\subsubsection{Enrichment of ketones}

In contrast with the extensive studies of phenols in bio-oil, ketones have been paid less attention.

There are few reports on the production of ketones from bio-oil. Ketones in SEB are mainly benzene ring-containing ketones (BRCKs), cyclopentenones (CPs) and furanones (DHF). As shown in Fig. 4 and Fig. 5, BRCKs were mainly enriched in $\mathrm{ES}_{\mathrm{b} 1}$ and $\mathrm{ES}_{\mathrm{d} 1}$. Acetophenone was isolated in $\mathrm{ES}_{\mathrm{b} 1}$, with an area $\%$ of $71.2 \%$. After two weeks, a faint yellow crystalline solid appeared on the wall of the container but it was failed to analyze the crystalline. Acetophenone is widely used as an industrial solvent for fiber/resin and an important stock used to produce chemicals such as benzoic acid, benzoylformic acid, dibenzoylfunzan 2-oxide, phenylethanol, phenol, and ethylbenzene, which have well-established industrial applications. Different from the BRCKs in $\mathrm{ES}_{\mathrm{b} 1}$, BRCKs in $\mathrm{ES}_{\mathrm{d} 1}$ were mainly hydroxyl- acetophenones, with an area $\%$ of $15.8 \%$.

CPs is another type of ketones in SEB, which possibly generated from cellulose and hemicellulose[28]. CPs can be used as chemical intermediates and food additives for flavor enhancement. In this study, CPs was mainly collected in $\mathrm{ES}_{\mathrm{b} 2}$ and $\mathrm{ES}_{\mathrm{d} 4}$ with an area \% of 25.9\% and 52.6\%, respectively. As shown in Fig. 4, most of CPs collected were HCPs with alkyl substituents. Two main HCPs in $\mathrm{ES}_{\mathrm{d} 4}$ were 2-hydroxy-3,4-dimethylcyclopentenone and 
2-hydroxy-3-ethylcyclopentenone with an area $\%$ of $12.2 \%$ and $25.8 \%$, respectively.

\section{Conclusions}

In total, 121 compounds were detected in SEB produced by ethanolysis of wheat stalk.

Oxy-compounds especially esters and phenols were dominant. The combination of extraction and liquid column chromatography was employed to separate SEB systematically. $\mathrm{C}_{8}-\mathrm{C}_{30}$ alkanes were separated in PE eluted fractions. Phenols were divided into four fractions, with the phenol concentration up to $\sim 100 \%$. Catechols, guaiacols and syringol were isolated in sub-fractions $\mathrm{ES}_{\mathrm{b} 2}$ $(55.6 \%), \mathrm{ES}_{\mathrm{d} 2}(95.7 \%)$, and $\mathrm{ES}_{\mathrm{d} 3}(57.2 \%)$, respectively. Acetophenone was successfully isolated in $\mathrm{ES}_{\mathrm{b} 1}(71.2 \%)$, while HCPs were also efficiently collected in $\mathrm{ES}_{\mathrm{d} 4}(52.6 \%)$. Future work is going to improve the recovery efficiency of ketones and quantify the recovered chemicals from SEB.

\begin{tabular}{ll} 
Abbreviations & \\
\hline Abbreviation & Full name/description \\
\hline SEB & Bio-oil produced from supercritical ethanol \\
$\mathrm{CS}_{2}$ & Carbon disulfide \\
DEE & Diethyl ether \\
PE & Petroleum ether \\
BRCKs & Benzene ring-containing ketones \\
CPs & Cyclopentenones \\
HCPs & Hydroxy-cyclopentenones \\
DHF & Furanones \\
NaOH & Sodium hydroxide \\
HCl & Hydrogen chloride \\
PHBs & Polyhydroxyl benzenes \\
MHBs & Monohydroxyl benzenes \\
PE & Petroleum ether \\
SG & Silica gel \\
GC-MS & Gas chromatography-mass spectrometry \\
TIC & Total iron chromatography \\
FTIR & Fourier transform infrared spectroscopy
\end{tabular}




\begin{tabular}{ll} 
BIP & Benzene insoluble phase \\
WP $_{\mathrm{I}}$ & Water phase I \\
BSP $_{\mathrm{I}}$ & Benzene phase I \\
DEEP $_{\mathrm{I}}$ & DEE soluble phase I extracted from WP \\
DEEIP $_{\mathrm{I}}$ & DEE insoluble phase I extracted from acidified aqueous by HCl \\
BSP $_{\mathrm{II}}$ & Benzene phase II \\
DEEP $_{\mathrm{II}}$ & DEE soluble phase II extracted from acidified aqueous by HCl \\
DEEIP $_{\mathrm{II}}$ & DEE insoluble phase II extracted from acidified aqueous by $\mathrm{HCl}$ \\
ES $_{\mathrm{bn}}$ & Fractions eluted from DEEP \\
ES $_{\mathrm{dn}}$ & Fractions eluted from DEEP \\
ES $_{\mathrm{cn}}$ & Fractions eluted from BSP \\
ES $_{\mathrm{cn}-\mathrm{w}}$ & Milk-white solids obtained from $\mathrm{ES}_{\mathrm{cn}}$ \\
$\mathrm{ASP}$ & Acetone soluble phase \\
AIP & Acetone insoluble phase \\
\hline
\end{tabular}

\section{Acknowledgements}

This work was subsidized by National Basic Research Program of China (Grant 2012CB215302), the Fund from Natural Science Foundation of China for Innovative Research Group (Grant 51221462), the Fundamental Research Funds for Central Universities (China University of Mining \& Technology; Grant 2013XK05), and a Project Funded by the Priority Academic Program Development of Jiangsu Higher Education Institutions. WZ and KN acknowledge the support by MOST-JST, Strategic International Collaborative Research Program, SICORP.

\section{References}

[1] G.W. Huber, S. Iborra, A. Corma, Synthesis of transportation fuels from biomass: Chemistry, catalysts, and engineering, Chem. Rev. 106 (2006) 4044-4098.

[2] F.X. Zeng, W.J. Liu, H. Jiang, H.Q. Yu, R.J. Zeng, Q.X. Guo, Separation of phthalate esters from bio-oil derived from rice husk by a basification-acidification process and column 
chromatography, Bioresour. Technol. 102 (2011) 1982-1987.

[3] C.B. Xu, T. Etcheverry, Hydro-liquefaction of woody biomass in sub- and super-critical ethanol with iron-based catalysts, Fuel 87 (2008) 335-345.

[4] D. Mohan, C.U. Pittman, P.H. Steele, Pyrolysis of wood/biomass for bio-oil: A critical review, Energy Fuels 20 (2006) 848-889.

[5] A.V. Bridgwater, D. Meier, D. Radlein, An overview of fast pyrolysis of biomass, Org. Geochem. 30 (1999) 1479-1493.

[6] A.V. Bridgwater, Review of fast pyrolysis of biomass and product upgrading, Biomass Bioenergy 38 (2012) 68-94.

[7] S.R. Wang, Y.R. Wang, Q.J. Cai, X.Y. Wang, H. Jin, Z.Y. Luo, Multi-step separation of monophenols and pyrolytic lignins from the water-insoluble phase of bio-oil, Sep. Purif. Technol. 122 (2014) 248-255.

[8] C.R. Vitasari, G.W. Meindersma, A.B. de Haan, Water extraction of pyrolysis oil: The first step for the recovery of renewable chemicals, Bioresour. Technol. 102 (2011) 7204-7210.

[9] A.S. Pollard, M.R. Rover, R.C. Brown, Characterization of bio-oil recovered as stage fractions with unique chemical and physical properties, J. Anal. Appl. Pyrolysis 93 (2012) 129-138.

[10] C. Amen-Chen, H. Pakdel, C. Roy, Separation of phenols from Eucalyptus wood tar, Biomass Bioenergy 13 (1997) 25-37.

[11] Z.G. Guo, S.R. Wang, Y.L. Gu, G.H. Xu, X. Li, Z.Y. Luo, Separation characteristics of biomass pyrolysis oil in molecular distillation, Sep. Purif. Technol. 76 (2010) 52-57. 
[12] A.T. Gooty, D.B. Li, C. Briens, F. Berruti, Fractional condensation of bio-oil vapors produced from birch bark pyrolysis, Sep. Purif. Technol. 124 (2014) 81-88.

[13] J.N. Murwanashyaka, H. Pakdel, C. Roy, Seperation of syringol from birch wood-derived vacuum pyrolysis oil, Sep. Purif. Technol. 24 (2001) 155-165.

[14] X.J. Guo, S.R. Wang, Z.G. Guo, Q.A. Liu, Z.Y. Luo, K.F. Cen, Pyrolysis characteristics of bio-oil fractions separated by molecular distillation, Appl. Energy 87 (2010) 2892-2898.

[15] S.R. Wang, Y. L. Gu, Q. Liu, Y. Yao, Z.G. Guo, Z.Y. Luo, K.F. Cen, Separation of bio-oil by molecular distillation, Fuel Process. Technol. 90 (2009) 738-745.

[16] C.B. Rasrendra, B. Girisuta, H.H. van de Bovenkamp, J.G.M. Winkelman, E.J. Leijenhorst, R. H. Venderbosch, M. Windt, D. Meier, H.J. Heeres, Recovery of acetic acid from an aqueous pyrolysis oil phase by reactive extraction using tri-n-octylamine, Chem. Eng. J. 176 (2011) 244-252.

[17] C.R. Vitasari, G.W. Meindersma, A.B. de Haan, Glycolaldehyde co-extraction during the reactive extraction of acetic acid with tri-n-octylamine/2-ethyl-1-hexanol from a wood-based pyrolysis oil-derived aqueous phase, Sep. Purif. Technol. 95 (2012) 39-43.

[18] N.M. Bennett, S.S. Helle, S.J.B. Duff, Extraction and hydrolysis of levoglucosan from pyrolysis oil, Bioresour. Technol. 100 (2009) 6059-6063.

[19] J.H. Li, C. Wang, Z.Y. Yang, Production and separation of phenols from biomass-derived bio-petroleum, J. Anal. Appl. Pyrolysis 89 (2010) 218-224.

[20] L.F. Zilnik, A. Jazbinsek, Recovery of renewable phenolic fraction from pyrolysis oil, Sep. 
Purif. Technol. 86 (2012) 157-170.

[21] Y. Wei, H.W. Lei, L. Wang, L. Zhu, X.S. Zhang, Y.P. Liu, S.L. Chen, B. Ahring, Liquid-liquid extraction of biomass pyrolysis bio-oil, Energy Fuels 28 (2014) 1207-1212.

[22] P. Das, T. Sreelatha, A. Ganesh, Bio oil from pyrolysis of cashew nut shell-characterisation and related properties, Biomass Bioenergy 27 (2004) 265-275.

[23] C. Acikgoz, O.M. Kockar, Characterization of slow pyrolysis oil obtained from linseed (Linum usitatissimum L.), J. Anal. Appl. Pyrolysis 85 (2009) 151-154.

[24] O. Onay, A.F. Gaines, O.M. Kockar, M.Adams, T.R. Tyagi, C.E. Snape, Comparison of the generation of oil by the extraction and the hydropyrolysis of biomass, Fuel 85 (2006) 382-392.

[25] A.E. Putun, E. Apaydin, E. Putun, Bio-oil production from pyrolysis and steam pyrolysis of soybean-cake: product yields and composition, Energy 27 (2002) 703-713.

[26] A.E. Putun, E. Apaydin, E. Putun, Rice straw as a bio-oil source via pyrolysis and steam pyrolysis, Energy 29 (2004) 2171-2180.

[27] H.M. Yang, W. Zhao, Y.G. Wang, D. Liu, J. Zhao, X. Fan, Z.M. Zong, Y. Lu, X.Y. Wei, Enrichment and identification of condensed aromatics in a bio-oil from degraded wheat stalk in supercritical ethanol, Energy Fuels 27 (2013) 596-598.

[28] W. Zhao, W.J. Xu, X.J. Lu, C. Sheng, S.T. Zhong, S.R. Tang, Z.M. Zong, X.Y. Wei, Preparation and property measurement of liquid fuel from supercritical ethanolysis of wheat stalk, Energy Fuels 24 (2010) 136-144. 


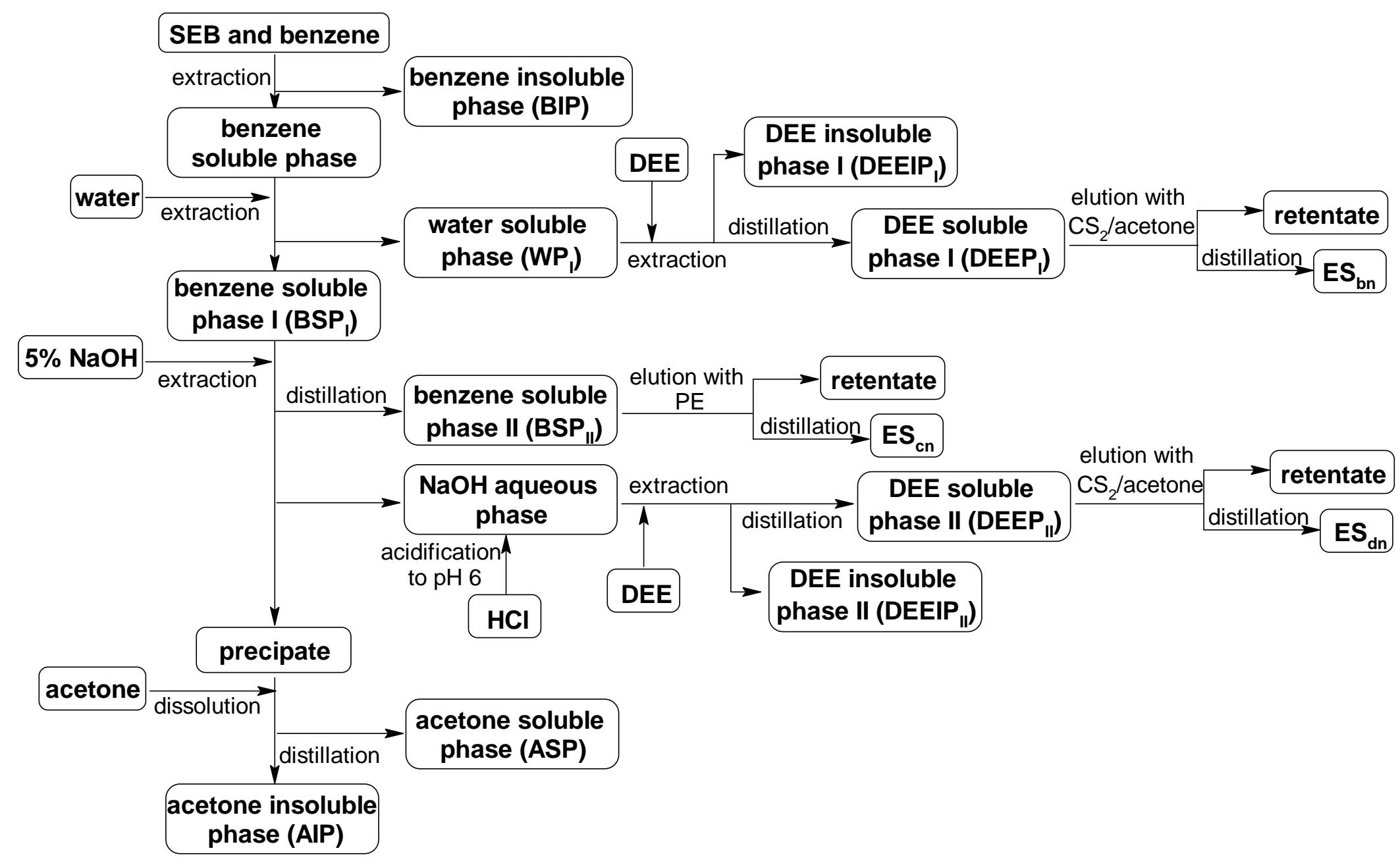

Fig. 1. Schematic diagram for the separation of SEB. 


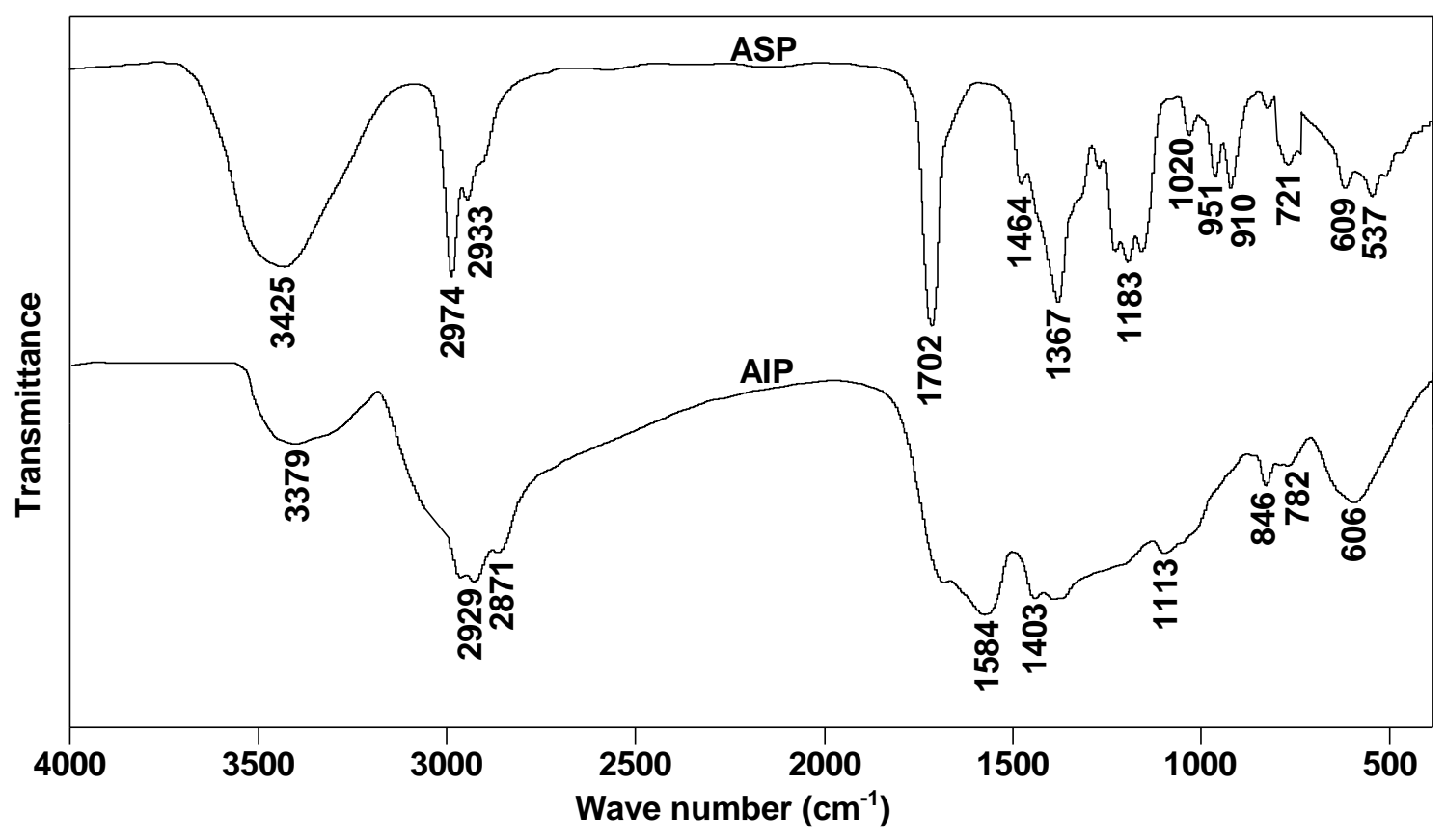

Fig. 2. FTIR spectra of ASP and AIP. 


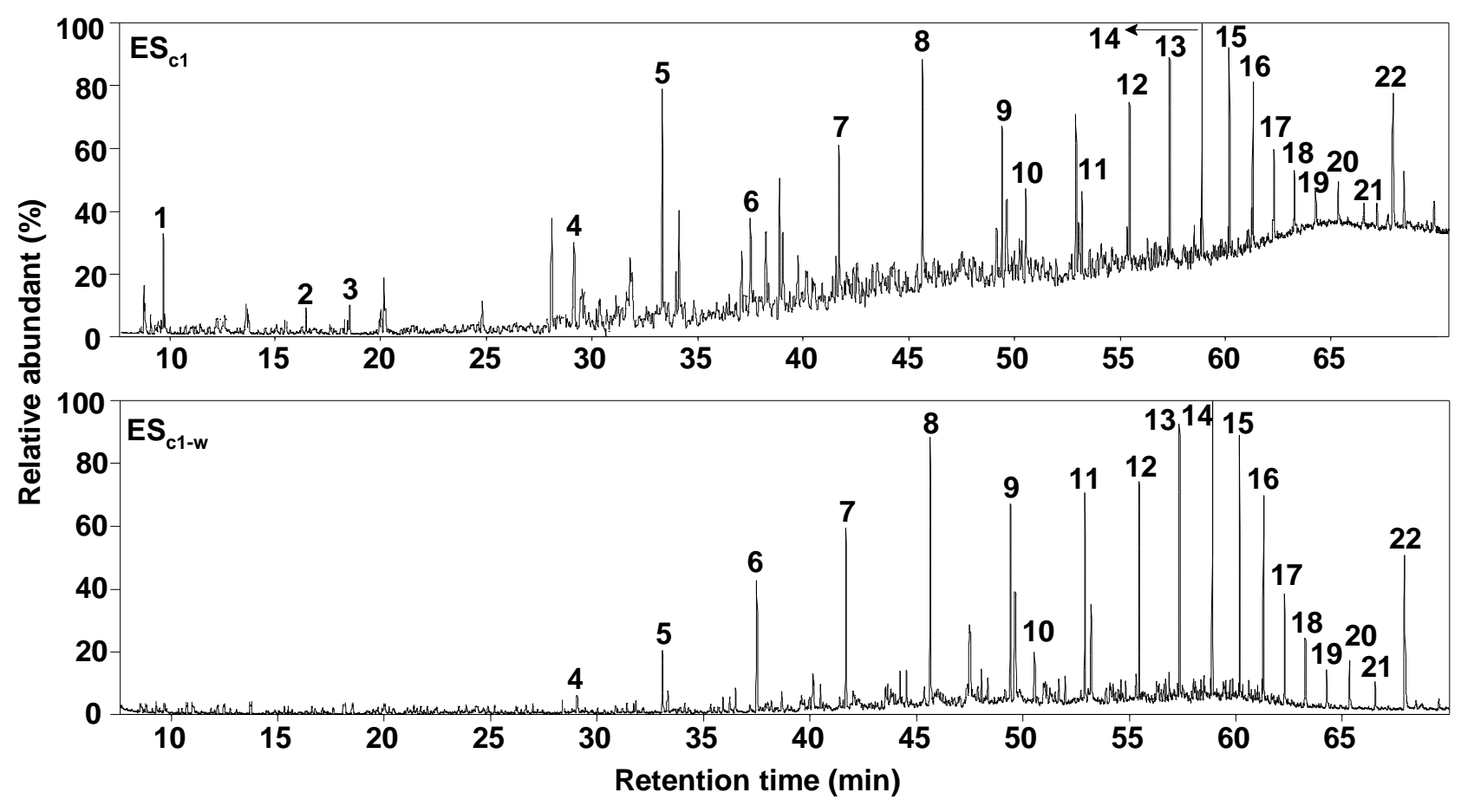

Fig. 3. TICs of $\mathrm{ES}_{\mathrm{c} 1}$ and $\mathrm{ES}_{\mathrm{c1-w}}$. 

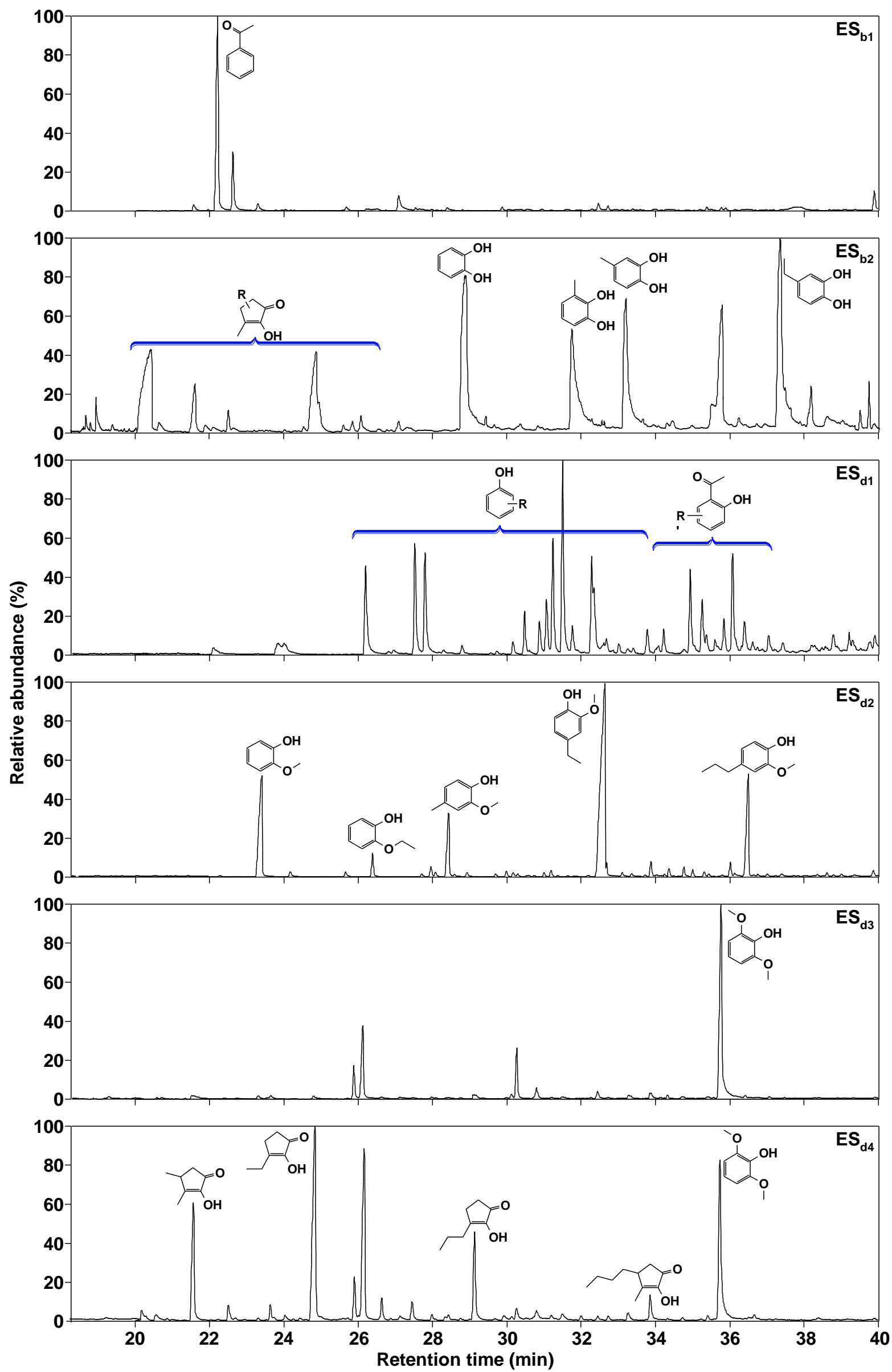

Fig. 4. TICs of $E S_{b n}$ and $E S_{d n}$. 


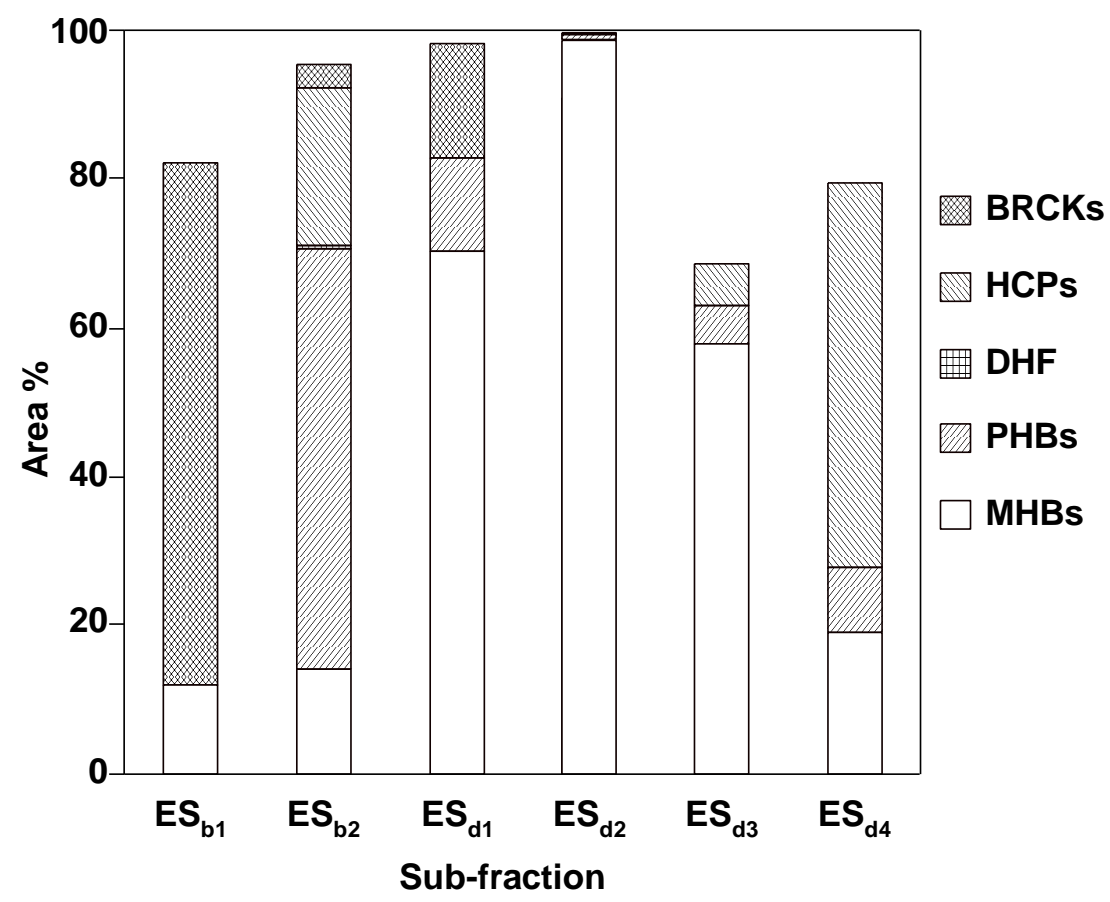

Fig. 5. Distribution of phenols and ketones in each $\mathrm{ES}_{\mathrm{bn}}$ and $\mathrm{ES}_{\mathrm{dn}}$. 
Table 1. Summary of Bio-oil Separation by Extraction and Column Chromatography

\begin{tabular}{|c|c|c|c|}
\hline & Bio-oil & Solvent & Separation fraction \\
\hline \multicolumn{4}{|l|}{ Extraction } \\
\hline $\begin{array}{l}\text { Rasrendra et } \\
\text { al. [16] }\end{array}$ & $\begin{array}{l}\text { An aqueous pyrolysis oil } \\
\text { from forest residue }\end{array}$ & $\begin{array}{l}\text { Batch liquid-liquid reactive extraction and } \\
\text { continuous reactive extractions with } \\
\text { Tri-n-octylamine in 2-ethyl-hexanol }\end{array}$ & $\begin{array}{l}86 \% \text { acetic acid was recovered by batch extraction, while } \\
\text { acetic acid recoveries of } 51 \% \text { and } 71 \% \text { were obtained in a } \\
\text { single CCS device and a two stage cross cascade. }\end{array}$ \\
\hline $\begin{array}{l}\text { Vitasari et al. } \\
{[17]}\end{array}$ & $\begin{array}{l}\text { Aqueous model mixture for } \\
\text { aqueous fast pyrolysis oil }\end{array}$ & $\begin{array}{l}\text { Bio-oil was extracted by } \\
\text { tri-n-ctylamine/2-ethyl-1-hexanol }\end{array}$ & $\begin{array}{l}\text { Co-extraction of glycolaldehyde and acetic acid was tried } \\
\text { with tri-n-ctylamine/2-ethyl-1-hexanol. }\end{array}$ \\
\hline $\begin{array}{l}\text { Bennett et al. } \\
{[18]}\end{array}$ & $\begin{array}{l}\text { Pyrolysis oil prepared by } \\
\text { VTT processes from scots } \\
\text { pine feedstock }\end{array}$ & $\begin{array}{l}\text { Bio-oil was extracted by water with different } \\
\text { water/oil ratio. }\end{array}$ & $\begin{array}{l}\text { Optimal extraction conditions ( } 41 \mathrm{wt} \% \text { water, } 34^{\circ} \mathrm{C} \text { ) } \\
\text { produced an aqueous extract with a concentration of up to } 88 \\
\mathrm{~g} / \mathrm{L} \text { levoglucosan. }\end{array}$ \\
\hline $\begin{array}{l}\text { Wang et al. } \\
\text { [7] }\end{array}$ & $\begin{array}{l}\text { Bio-oil from lauan sawdust } \\
\text { via fluidized bed pyrolysis }\end{array}$ & $\begin{array}{l}\text { Extraction by water, and } \mathrm{NaOH} \text { solution }(\mathrm{pH}=14) \text {, } \\
\text { dichloromethane }\left(\mathrm{CH}_{2} \mathrm{Cl}_{2}\right) \text {. } \mathrm{HCl} \text { solution to adjust } \\
\mathrm{pH} \text {. }\end{array}$ & $\begin{array}{l}\text { Fraction with a high concentration of } 94.35 \% \text { phenolic } \\
\text { compounds was obtained. Pyrolytic lignins were analyzed in } \\
\text { the raffinate after extraction. }\end{array}$ \\
\hline $\begin{array}{l}\text { Amen-Chen et } \\
\text { al. [10] }\end{array}$ & $\begin{array}{l}\text { Bio-oil converted from } \\
\text { Eucalyptus wood tar }\end{array}$ & $\begin{array}{l}\text { Dissolution in ethyl acetate, extraction by } \mathrm{NaOH} \\
\text { solution, acidification of aqueous phase to } \mathrm{pH} 6 \text {, } \\
\text { and then extraction of ethyl acetate. }\end{array}$ & $\begin{array}{l}\text { Complete recovery of phenols was achieved at a pH of 12-13 } \\
\text { by using a concentrated alkaline solution. }\end{array}$ \\
\hline Li et al. [19] & $\begin{array}{l}\text { Bio-oil from corn stalk } \\
\text { directly deoxy-liquefied }\end{array}$ & $\begin{array}{l}\text { Distillation under vacuum. } \\
\text { Extraction of } 180-260{ }^{\circ} \mathrm{C} \text { fraction by mixing with } \\
\mathrm{NaOH} \text { solution and } \mathrm{HCl} \text { solution. }\end{array}$ & $\begin{array}{l}\text { The high-purity phenol derivatives, such as phenol, cresols, } \\
\text { guaiacol, 4-methyl guaiacol and syringol were obtained. }\end{array}$ \\
\hline $\begin{array}{l}\text { Zilnik et al. } \\
\text { [20] }\end{array}$ & $\begin{array}{l}\text { Bio-oils produced by fast } \\
\text { pyrolysis process of wood } \\
\text { and forest residues }\end{array}$ & $\begin{array}{l}\text { Two schemes were considered: one is starting } \\
\text { with an aqueous extraction (water, aqueous } \\
\mathrm{NaHSO}_{3} \text {, or alkali solution), another one with } \\
\text { simultaneous use of a hydrophobic-polar solvent } \\
\text { (such as MIKB or ethyl acetate) and anti-solvent }\end{array}$ & $\begin{array}{l}\text { Phenolics were recovered from pyrolysis oil. The distribution } \\
\text { coefficients and extraction factors of phenolic compounds } \\
\text { were compared for different solvents. MIBK was the most } \\
\text { efficient solvent for extraction of phenolics from bio-oil in } \\
\text { combination with aqueous } \mathrm{NaOH} \text { solution. }\end{array}$ \\
\hline
\end{tabular}


alkali solution).

Wei et al. [21] Bio-oil from microwave pyrolysis
Water, and then organic solvent (hexane, petrolem ether, chloroform).

Elution by hexane-ethyl acetate mixture and chloroform-methanol mixtures.

\section{Extraction by n-pentane, 2. Elution with} pentane, toluene, and methanol.

Elution by n-hexane, toluene and

dichloromethane/methanol (1:1, v/v) linseed and hazelnut shell via slow hydropyrolysis

Zeng et al. [2] Bio-oil from rice husk via fluidized bed fast pyrolysis

Putun et al. Bio-oil from soybean-cake via pyrolysis and steam pyrolysis

Putun et al. Bio-oil from rice straw via [26]

Extraction by saturated $\mathrm{NaOH}$ solution, and then acidified by $\mathrm{HCl}$ solution to get solid precipitate. The solid precipitate was separated by column eluated by ethyl acetate (EA) and ethanol or mixture of EA/petroleum ether or EA/ethanol.

Elution with pentane, toluene, ether and methanol. pyrolysis and steam pyrolysis
The phenols and guaiacols were recovered at efficiency of $85 \%$ in the extracted phase by water-chloroform extraction.

Five purified compounds (cardanol, cardol, di-n-octyl phthalate, bis (2-ethylhexyl) phthalate, and di-n-decyl phthalate) were obtained.

$88 \mathrm{wt} \%$ of bio-oil was extracted in n-pentane soluble. Aliphatic $\left(\mathrm{C}_{13}-\mathrm{C}_{29}\right)$, aromatic and polar fractions account for 30,34 and $36 \mathrm{wt} \%$ of the n-pentane soluble, respectively. Aliphatic (predominantly $\mathrm{C}_{13}-\mathrm{C}_{30} \mathrm{n}$-alkanes), aromatic and polar fractions were obtained.

Aliphatic (alkanes, alkenes, and branched hydrocarbons), aromatic, ester and polar fractions were abtained.

Elution of pentane soluble materials gave aliphatic, aromatic, ester and polar fractions. 
Table 2. Main Components in SEB (Area\% $\geq 1 \%$ ).

\begin{tabular}{|c|c|c|}
\hline \multicolumn{2}{|c|}{ Peak $^{a}$ Compound } & Area $c$ \\
\hline \multicolumn{3}{|c|}{ Hydrocarbons } \\
\hline 43 & 2,5-Dimethylhexa-1,5-diene & 2.8 \\
\hline 110 & 4-Propyl-1,1'-biphenyl & 1.5 \\
\hline \multicolumn{3}{|c|}{ Phenols } \\
\hline 40 & Phenol & 1.7 \\
\hline 51 & 3-Cresol & 1.3 \\
\hline 55 & 4-Methoxyphenol & 4.1 \\
\hline 73 & 4-Ethylphenol & 3.2 \\
\hline 78 & 4-Methylguaiacol & 1.7 \\
\hline 84 & 1,2,3-Benzenetriol & 2.9 \\
\hline 89 & 4-Ethylguaiacol & 4.2 \\
\hline 99 & Syringol & 2.6 \\
\hline 102 & 4-Propylguaiacol & 1.6 \\
\hline
\end{tabular}

Ethers

$\begin{array}{cll}\mathbf{4 1} & \text { 2-Ethoxy-2-methylbutane } & 1.2 \\ \mathbf{6 8} & \text { Ethoxybenzene } & 1.6 \\ \mathbf{1 0 9} & \text { 1,2,3-Trimethoxy-5-toluene } & 1.4\end{array}$

Furan derivates

3 Tetrahydrofuran $\quad 3.8$

16 2-Ethoxytetrahydrofuran 4.0

23 Furan-2-ylmethanol 1.1

31 Dihydrofuran-2(3H)-one 1.6

Esters

1 Ethyl acetate $\quad 1.0$

15 Ethyl 2-hydroxypropanoate 2.8

29 Ethyl 2-hydroxybutanoate 5.2

54 Pentan-2-yl butyrate 11.5

88 Diethyl glutarate 1.3

115 Ethyl palmitate $\quad 1.2$

Alkanoic Acid

2 Acetic acid 1.1

${ }^{a}$ refers to the number marked in Fig. SI1. 
Table 3. Extract Yields $(w t \%)$ from SEB

\begin{tabular}{cccccccc}
\hline BIP & DEEP $_{\mathrm{I}}$ & DEEIP $_{\mathrm{I}}$ & DEEP $_{\| I}$ & DEEIP $_{\text {II }}$ & BSP $_{\text {II }}$ & ASP & AIP \\
\hline 42.5 & 5.0 & 0.3 & 10.0 & 5.0 & 17.5 & 2.5 & 10.0 \\
\hline
\end{tabular}


Table 4. Main Compounds Detected in $\mathrm{BSP}_{\mathrm{II}}($ Area $\% \geq 1 \%$ ).

\begin{tabular}{|c|c|c|}
\hline Peak $^{b}$ & Compounds & Area $\%$ \\
\hline 2 & Ethylbenzene & 2.0 \\
\hline 3 & 2-Methylcyclopentenone & 2.6 \\
\hline 5 & 1,2-Dimethylcyclopentenone & 1.1 \\
\hline 10 & 3,4-Dimethylcyclopentenone & 1.3 \\
\hline 11 & 2,5-Dimethylcyclopentenone & 3.9 \\
\hline 14 & Acetophenone & 1.2 \\
\hline 17 & 2,3-Dimethylcyclopentenone & 3.2 \\
\hline 19 & 2,3,4-Trimethylcyclopentenone & 1.3 \\
\hline 20 & 3-Ethylcyclopentenone & 2.0 \\
\hline 22 & Hydrindane & 2.0 \\
\hline 23 & 4-Methoxylphenol & 1.2 \\
\hline 27 & Propyl cyclohexene & 1.7 \\
\hline 31 & 2-Methyl-4-octyne & 1.5 \\
\hline 37 & Ethyl benzoate & 1.3 \\
\hline 39 & 2-Methyl-diethyl succinate & 4.0 \\
\hline 40 & Diethyl glutarate & 1.1 \\
\hline 41 & Decalin & 1.9 \\
\hline 42 & Furyl-2- butanone & 2.7 \\
\hline 43 & Diethyl 3-methyl glutarate & 1.8 \\
\hline 44 & 1,4-Dimethoxyl-2-methylbenzene & 1.4 \\
\hline 45 & 2-Ethylfurfural & 1.4 \\
\hline 46 & 3-Methyl-2-vinylcyclohexanone & 1.1 \\
\hline 47 & Ethyl 4-methoxyl benzoate & 1.6 \\
\hline 51 & 1-Methoxyl-3,5-dimethylbenzene & 1.7 \\
\hline 52 & Diethyl adipate & 3.6 \\
\hline 53 & Ethyl 3-methyl benzoate & 1.1 \\
\hline 55 & Ethyl 4-methyl benzoate & 1.1 \\
\hline 58 & 3-Methyl-2,3-indenone & 1.5 \\
\hline 59 & 4-Methylthioacetophenone & 1.4 \\
\hline 61 & 1-Propyl-4-methyl-2-methoxylbenzene & 1.2 \\
\hline 64 & 4-tert-Butylbenzyl alcohol & 1.3 \\
\hline 67 & 1,3-Dimethyl-5-vinylbenzene & 1.1 \\
\hline 68 & 4-tert-Butylacetophenone & 1.1 \\
\hline 69 & 3,4-Dimethoxylacetophenone & 1.4 \\
\hline 73 & Ethyl tetradecanoate & 1.3 \\
\hline 77 & Ethyl palmitate & 2.1 \\
\hline
\end{tabular}


Table 5. Main Compounds Detected in $\operatorname{DEEP}_{\mathrm{I}}($ Area $\% \geq 1 \%$ ).

\begin{tabular}{|c|c|c|}
\hline Peak $^{c}$ & Compound & Area $\%$ \\
\hline 1 & Butan-2-ol & 1.2 \\
\hline 3 & Tetrahydrofuran & 1.3 \\
\hline 10 & 2-Ethoxybutane & 1.5 \\
\hline 11 & Ethyl 2-hydroexypropanoate & 3.1 \\
\hline 12 & 2-Ethoxypentane & 1.8 \\
\hline 14 & 4-Hydroxy-4-methylpentan-2-one & 1.3 \\
\hline 15 & But-2-enoic acid & 7.1 \\
\hline 16 & Ethyl 2-hydroxybutanoate & 4.9 \\
\hline 20 & Phenol & 3.7 \\
\hline 21 & Ethyl 2-hydroxypentanoate & 1.2 \\
\hline 22 & 3-Methylcyclopentane-1,2-dione & 4.4 \\
\hline 24 & 2-Hydroxy-3,4-dimethylcyclopent-2-enone & 2.4 \\
\hline 25 & Acetophenone & 15.4 \\
\hline 26 & (Tetrahydrofuran-2-yl)methyl acetate & 7.1 \\
\hline 27 & 2-Methoxyphenol & 2.6 \\
\hline 28 & 3-Ethyl-2-hydroxycyclopent-2-enone & 4.2 \\
\hline 29 & 2-(Methylthio)phenol & 1.1 \\
\hline 30 & 6-Oxo-6H-pyran-3-carboxylic acid & 1.5 \\
\hline 31 & Isopropyl butyl ether & 1.2 \\
\hline 32 & 4-Ethylphenol & 1.4 \\
\hline 34 & Catechol & 5.3 \\
\hline 36 & 3-Ethylcatechol & 3.2 \\
\hline 38 & 4-Methylcatechol & 2.3 \\
\hline 40 & 4-Ethylcatechol & 1.7 \\
\hline 41 & Syringol & 3.6 \\
\hline 42 & 4-Ethylcatechol & 3.3 \\
\hline
\end{tabular}

${ }^{c}$ refers to the number marked in Fig. SI3. 
Table 6. Main Compounds Detected in $\operatorname{DEEP}_{\mathrm{II}}$ (Area $\% \geq 1 \%$ ).

\begin{tabular}{|c|c|c|}
\hline Peak $^{d}$ & Compound & Area $\%$ \\
\hline 4 & Ethyl acetate & 1.8 \\
\hline 7 & 2-Ethoxybutane & 9.1 \\
\hline 11 & Phenol & 2.6 \\
\hline 13 & 2,3-Xylenol & 1.5 \\
\hline 14 & 2-Hydroxy-3,4-dimethylcyclopent-2-enone & 1.5 \\
\hline 15 & $p$-Cresol & 2.1 \\
\hline 16 & Tetrahydrofuran-2-ol & 1.7 \\
\hline 17 & Guaiacol & 12.8 \\
\hline 18 & 3-Ethyl-2-hydroxycyclopent-2-enone & 3.4 \\
\hline 19 & 2-Ethylphenol & 1.7 \\
\hline 20 & 3,5-Dimethoxyphenol & 1.7 \\
\hline 21 & 2-Ethoxyphenol & 2.6 \\
\hline 22 & 6-Oxo-6H-pyran-3-carboxylic acid & 2.5 \\
\hline 23 & 4-Ethoxyphenol & 11.0 \\
\hline 25 & 4-Methylcatechol & 1.3 \\
\hline 27 & 4-Methylguaiacol & 4.0 \\
\hline 31 & 3-Ethyl- 5-cresol & 4.9 \\
\hline 35 & 4-Ethylguaiacol & 15.2 \\
\hline 36 & 5-Isopropyl -2-cresol & 1.5 \\
\hline 42 & Syringol & 9.6 \\
\hline 44 & 3,4-Xylenol & 4.2 \\
\hline
\end{tabular}

${ }^{d}$ refers to the number marked in Fig. SI4 
Table 7. Alkanes Separated in $\mathrm{ES}_{\mathrm{c} 1}$ and $\mathrm{ES}_{\mathrm{c} 2}$ from the SEB.

\begin{tabular}{llcc}
\hline \multirow{2}{*}{ Peak $^{e}$} & \multirow{2}{*}{ Compound } & \multicolumn{2}{c}{ Area $\%$} \\
\cline { 3 - 4 } & & $\mathrm{ES}_{\mathrm{c} 1}$ & $\mathrm{ES}_{\mathrm{c} 2}$ \\
\hline $\mathbf{1}$ & Octane & 1.5 & 0.6 \\
$\mathbf{2}$ & Nonane & 1.7 & \\
$\mathbf{3}$ & Decane & 0.7 & \\
$\mathbf{4}$ & Dodecane & 1.2 & \\
$\mathbf{5}$ & Tridecane & 1.7 & \\
$\mathbf{6}$ & Tetradecane & 2.8 & \\
$\mathbf{7}$ & Pentadecane & 5.1 & \\
$\mathbf{8}$ & Hexadecane & 6.3 & \\
$\mathbf{9}$ & Heptadecane & 3.9 & \\
$\mathbf{1 0}$ & Octadecane & 3.4 & 5.4 \\
$\mathbf{1 1}$ & Nonadecane & 3.1 & 5.1 \\
$\mathbf{1 2}$ & Icosane & 3.0 & 11.7 \\
$\mathbf{1 3}$ & Henicosane & 3.2 & 12.8 \\
$\mathbf{1 4}$ & Docosane & 3.0 & 11.7 \\
$\mathbf{1 5}$ & Tricosane & 3.0 & 8.5 \\
$\mathbf{1 6}$ & Tetracosane & 2.0 & 7.4 \\
$\mathbf{1 7}$ & Pentacosane & 1.6 & 6.3 \\
$\mathbf{1 8}$ & Hexacosane & 1.6 & 6.8 \\
$\mathbf{1 9}$ & Heptacosane & 0.9 & 6 \\
$\mathbf{2 0}$ & Octacosane & 1.2 & 6.1 \\
$\mathbf{2 1}$ & Nonacosane & 1.3 & 4.7 \\
$\mathbf{2 2}$ & Triacontane & 3.7 & 4.1 \\
Total & & 55.9 & 97.2 \\
\hline \multicolumn{2}{c}{${ }^{e}$ refers to the number marked in Fig. 4.} \\
\hline
\end{tabular}


Table 8. Phenols Detected in $\mathrm{ES}_{\mathrm{bn}}$ and $\mathrm{ES}_{\mathrm{dn}}$.

\begin{tabular}{|c|c|c|c|c|c|c|c|}
\hline \multirow{2}{*}{ Peak $^{f}$} & \multirow{2}{*}{ Compound } & \multicolumn{6}{|c|}{ Area \% } \\
\hline & & $\mathrm{ES}_{\mathrm{b} 1}$ & $\mathrm{ES}_{\mathrm{b} 2}$ & $\mathrm{ES}_{\mathrm{d} 1}$ & $\mathrm{ES}_{\mathrm{d} 2}$ & $\mathrm{ES}_{\mathrm{d} 3}$ & $\mathrm{ES}_{\mathrm{d} 4}$ \\
\hline \multicolumn{8}{|l|}{$M H B S$} \\
\hline 11 & Guaiacol & & & & 18.6 & & \\
\hline 16 & 2-(Methylthio)phenol & & 0.7 & & & & \\
\hline 18 & 2-Ethoxyphenol & & & 7.3 & 2.4 & & \\
\hline 20 & 4-Ethylphenol & 11.3 & & & & & \\
\hline 22 & 6-Methyl guaiacol & & & 7.9 & & & \\
\hline 23 & 4-Ethyl-3-methoxyphenol & & & 7.6 & 1.1 & & \\
\hline 24 & 4-Methyl guaiacol & & & 3.9 & 8.3 & & \\
\hline 26 & 2,3,5-Trimethylphenol & & & 0.7 & & & \\
\hline 29 & 2,4,6-Trimethylphenol & & & 1.0 & & & \\
\hline 32 & 2-Ethoxy-4-cresol & & & 2.4 & & & \\
\hline 33 & 2-Isopropyl-4-cresol & & & 8.2 & & & \\
\hline 34 & 4-Ethyl guaiacol & & & 13.2 & 49.4 & 2.4 & \\
\hline 36 & 2-Propyl-4-cresol & & & 2.1 & & & \\
\hline 37 & Ethylxylenol & & & 5.9 & & & \\
\hline 38 & 4-Ethyl-3-methoxyphenol & & & 4.3 & & & \\
\hline 39 & 2-Isopropyl-5-cresol & & & 2.0 & & & \\
\hline 40 & 4-Isopropyl-3-cresol & & & & 1.7 & & \\
\hline 47 & Syringol & & 11.4 & & & 57.2 & 19.4 \\
\hline 49 & 4-Allyl guaiacol & & & & 1.5 & & \\
\hline 52 & 4-Propyl guaiacol & & & & 14.4 & & \\
\hline 53 & 2-Allyl-4-cresol & & & 1.8 & & & \\
\hline 57 & 2-tert-Butyl-4-methoxyphenol & & & 1.5 & & & \\
\hline \multicolumn{8}{|c|}{ PHBs } \\
\hline 8 & Benzene-1,3,5-triol & & 0.8 & & & & \\
\hline 12 & 2-Methoxyhydroquinone & & & & & 6.6 & 1.4 \\
\hline 15 & 3-Methoxycatechol & & & & & & 3.6 \\
\hline 19 & 2-Methoxyresorcinol & & & & & & 2.0 \\
\hline 25 & Catechol & & 16.3 & & & & \\
\hline 30 & 4-Methylcatechol & & 10.7 & 2.9 & & & \\
\hline 35 & 3-Methylcatechol & & 11.4 & & & & \\
\hline 42 & 2-tert-Butylhydroquinone & & & 1.9 & & & \\
\hline 44 & 4-Ethylresorcinol & & & & & & \\
\hline 50 & 4-tert-Butylcatechol & & & 7.7 & & & \\
\hline 54 & 4-Ethylcatechol & & 16.4 & & & & \\
\hline
\end{tabular}

${ }^{f}$ refers to the number marked in Fig. SI5. 
Table 9. Ketones Detected in $\mathrm{ES}_{\mathrm{bn}}$ and $\mathrm{ES}_{\mathrm{dn}}$

\begin{tabular}{|c|c|c|c|c|c|c|c|}
\hline \multirow{2}{*}{ Peak $^{g}$} & \multirow{2}{*}{ Compound } & \multicolumn{6}{|c|}{ Area $\%$} \\
\hline & & $\mathrm{ES}_{\mathrm{b} 1}$ & $\mathrm{ES}_{\mathrm{b} 2}$ & $\mathrm{ES}_{\mathrm{d} 1}$ & $\mathrm{ES}_{\mathrm{d} 2}$ & $\mathrm{ES}_{\mathrm{d} 3}$ & $\mathrm{ES}_{\mathrm{d} 4}$ \\
\hline \multicolumn{8}{|l|}{$D H F$} \\
\hline 1 & 5-Methyldihydrofuran-2(3H)-one & & 0.4 & & & & \\
\hline \multicolumn{8}{|c|}{ 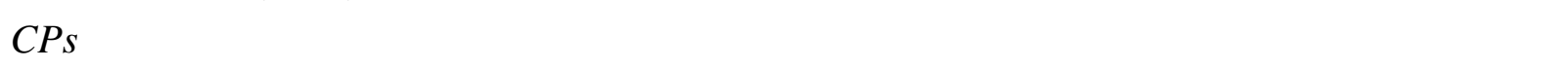 } \\
\hline 2 & 3-Methylcyclopent-2-enone & & 1.1 & & & & \\
\hline 3 & 3-Methylcyclopentane-1,2-dione & & & & & & 1.7 \\
\hline 4 & 2-Hydroxy-3-methylcyclopent-2-enone & & 11.2 & & & & \\
\hline 5 & 2-Hydroxy-3,4-dimethylcyclopent-2-enone & & & & & 1.5 & 12.2 \\
\hline 6 & 3-Hydroxy-2,4-dimethylcyclopent-2-enone & & 2.5 & & & & \\
\hline 9 & 2-Acetylcyclopentanone & & & & & & 1.6 \\
\hline 13 & 3-Ethyl-2-hydroxycyclopent-2-enone & & & & & 1.1 & 25.8 \\
\hline 14 & 2-Ethyl-3-hydroxycyclopent-2-enone & & 7.6 & & & & \\
\hline 27 & 2-Hydroxy-3-propylcyclopent-2-enone & & & & & & 8.2 \\
\hline 41 & 3-Butyl-2-hydroxycyclopent-2-enone & & & & & & 3.1 \\
\hline \multicolumn{8}{|c|}{$B R C K s$} \\
\hline 7 & Acetophenone & 71.2 & & & & & \\
\hline 45 & 1-(2-Hydroxy-6-methoxyphenyl)ethanone & & & 5.8 & & & \\
\hline 46 & 1-(2,6-Dihydroxy-3-tolyl)ethanone & & & 4.1 & & & \\
\hline 48 & 1-(2-Hydroxy-5-methoxyphenyl)ethanone & & & 3.0 & & & \\
\hline 51 & 1-(2,4-Dihydroxyphenyl)propan-1-one & & & 2.9 & & & \\
\hline 58 & 1-(4-Hydroxy-3-methoxyphenyl)ethanone & & 1.3 & & & & \\
\hline 59 & 1-(4-Hydroxy-3-methoxyphenyl)propan-2-one & & 1.8 & & & & \\
\hline
\end{tabular}

${ }^{g}$ refers to the number marked in Fig. SI5. 